\title{
Reduction of parathyroid hormone with vitamin $D$ supplementation in blacks: a randomized controlled trial
}

\author{
Paulette D. Chandler ${ }^{1,2^{*}}$, Foluso Agboola ${ }^{3}$, Kimmie Ng ${ }^{2,4}$, Jamil B. Scott ${ }^{5}$, Bettina F. Drake ${ }^{6}$, Gary G. Bennett ${ }^{7}$, \\ Andrew T. Chan ${ }^{2,8}$, Bruce W. Hollis ${ }^{9}$, Karen M. Emmons ${ }^{2,10}$, Charles S. Fuchs ${ }^{2,4}$ and Edward L. Giovannucci ${ }^{2,11,12}$
}

\begin{abstract}
Background: Response of parathyroid hormone (PTH) to vitamin D supplementation is determined by the baseline PTH level and change in vitamin D status. Conflicting reports in Blacks exist on the PTH response to vitamin D to supplementation.

Methods: During 3 winters from 2007 to 2010, 328 healthy Blacks (median age, 51 years) living in Boston, MA were randomized into a 4-arm, double-blind trial for 3 months of placebo, 1000, 2000, or 4000 IU of vitamin D3. PTH was measured in 254 participants at baseline and at the end of vitamin D supplementation period.

Results: The differences in PTH between baseline and 3 months were $3.93 \mathrm{pg} / \mathrm{mL}$ for those receiving placebo, $-3.37 \mathrm{pg} / \mathrm{mL}$ for those receiving $1000 \mathrm{IU} / \mathrm{d},-6.76 \mathrm{pg} / \mathrm{mL}$ for those receiving $2000 \mathrm{IU} / \mathrm{d}$, and $-8.99 \mathrm{pg} / \mathrm{mL}$ for those receiving $4000 \mathrm{IU} / \mathrm{d}(-2.98 \mathrm{pg} / \mathrm{mL}$ for each additional $1000 \mathrm{IU} / \mathrm{d}$ of vitamin $\mathrm{D} 3 ; p<0.001)$.
\end{abstract}

Conclusion: We found a significant decrease in PTH with increasing doses of vitamin D supplementation up to intakes of $4000 \mathrm{IU} / \mathrm{d}$ in Blacks.

Trial registration: Clinical Trials.gov: NCT00585637

Keywords: Vitamin D, Parathyroid hormone, Blacks, Supplementation

\section{Background}

Blacks have significantly lower circulating 25hydroxyvitamin $\mathrm{D}[25(\mathrm{OH}) \mathrm{D}]$ and higher serum parathyroid hormone $[\mathrm{PTH}]$ concentrations than Whites $[1,2]$. Observational and intervention studies have shown that vitamin D deficiency and high serum PTH are associated with increased risk of skeletal disease [3, 4]. Paradoxically, Blacks have a lower risk of osteoporotic fractures partly because of skeletal resistance to PTH among other factors [5]. Recent studies have identified an association of high PTH with increased morbidity and mortality independent of bone disease [6]. In one study, elevated plasma PTH $(>50 \mathrm{pg} / \mathrm{mL})$ accounted for $20 \%$ of the population-attributable risk

\footnotetext{
*Correspondence: pchandler@partners.org

'Division of Preventive Medicine, Brigham and Women's Hospital, Third Floor, 900 Commonwealth Avenue, Boston, MA 02215, USA

${ }^{2}$ Harvard Medical School, Boston, MA, USA

Full list of author information is available at the end of the article
}

proportion for cardiovascular mortality [7]. A consensus conference on primary hyperparathyroidism suggested that large populations of vitamin D-replete cohorts are necessary to establish reference intervals for PTH assays [8]. Furthermore, there has been recent debate about what constitutes vitamin D deficiency and sufficiency [9]. The most recent compilation of data suggest $25(\mathrm{OH}) \mathrm{D}$ level of $20 \mathrm{ng} / \mathrm{mL}(50 \mathrm{nmol} / \mathrm{L}$ ) is adequate for the population. However, the 2011 Institute of Medicine (IOM) report concluded that there is currently only sufficient evidence to provide health guidelines for skeletal health. For extra skeletal outcomes, including cancer, cardiovascular disease (CVD), diabetes mellitus (DM) and autoimmune disorders, the evidence was inconsistent, inconclusive as to causality and insufficient to inform nutritional requirements $[10,11]$. The U.S. Preventive Services Task Force (USPSTF) concluded that the current evidence is insufficient to assess the balance of the benefits and 
harms of screening for vitamin D deficiency in asymptomatic adults [12]. Therefore, more data are needed to assess the need for vitamin D supplementation for non-skeletal outcomes and to identify potential threshold effects for non-skeletal outcomes given the current controversy about the role of PTH [13-16] and vitamin $\mathrm{D}$ in disease pathogenesis. Thus, understanding the role of vitamin D supplementation on PTH homeostasis is important.

The threshold for vitamin D sufficiency has been defined by some as the lowest serum concentration of 25(OH)D that maximally suppresses PTH secretion [17]. Several studies have reported varying individualized responses of Vitamin D supplementation on serum level of PTH $[18,19]$. Yet, these studies did not include a sufficient number of Blacks. Therefore, we conducted an ancillary analysis of the dose-response effect of 3 doses of vitamin D3 and placebo on PTH levels within a blinded randomized clinical trial (RCT) to show how PTH responds to different doses of vitamin D3.

\section{Methods}

The parent study was a prospective, randomized, double blind, placebo-controlled trial of oral vitamin D supplementation in healthy Blacks (Clinical Trials.gov: NCT00585637). The protocol has been described in detail previously [20]. The primary goal of the trial was to examine the effect of daily supplementation of 1000 international units (IU), $2000 \mathrm{IU}$, and $4000 \mathrm{IU}$ of vitamin D3 and placebo on plasma 25(OH)D levels. All participants provided written informed consent. The project was approved by the Institutional Review Boards of Harvard School of Public Health and the Dana-Farber Cancer Institute. All procedures were followed in accordance with the institutional guidelines.

\section{Recruitment and exclusion criteria}

Participants were 30 to 80 years old, understood written and spoken English and self-identified as Black or African-American [21-23]. Enrollment during the late autumn and winter months minimized the influence of sun exposure on vitamin D levels. A total of 328 individuals living in the Boston area were enrolled into the parent trial (Fig. 1). Exclusion criteria included pregnancy, renal disease, preexisting parathyroid, thyroid, or calcium metabolism disorders, sarcoidosis, requirement for calcium channel blockers, type I diabetes, active malignancies (other than non-melanoma skin cancer), and plan for extended travel to a sunny region during supplementation phase of the study. Primary care physicians of all enrolled participants were required to provide documentation that the participant had no prior history of hypercalcemia.

\section{Randomization and treatment}

Participants were randomly assigned to one of four treatment arms: placebo, $1000 \mathrm{IU}(25 \mathrm{mcg}) /$ day, $2000 \mathrm{IU}$ $(50 \mathrm{mcg}) /$ day, or $4000 \mathrm{IU}(100 \mathrm{mcg}) /$ day of vitamin D (as cholecalciferol). Treatment consisted of tablets that, in addition to placebo or vitamin $\mathrm{D}$, also contained $200 \mathrm{mg}$ of calcium carbonate. The tablets were formulated and manufactured by Pharmavite LLC (Mission Hill, California). Study medications were started during early winter (November or December) and were taken orally once a day for 3 months (completed in February or March) to minimize any effect of ultraviolet exposure in New England. Study statisticians generated the random allocation sequence. All participants, providers, and study staff were blinded.

\section{Endpoints and follow up}

The primary end point of the study was change in serum PTH from baseline to the 3-month end of randomized supplementation. Dietary intake of calcium and vitamin $\mathrm{D}$ was estimated by using a modified Food Frequency Questionnaire (FFQ) at baseline and 3 months.

\section{Safety and compliance}

Participants were followed for toxicity and compliance every 2 weeks by phone and every 4 weeks in person during supplementation. Study staff ascertained absence of symptoms (such as muscle aches, excessive thirst, frequent urination, and nausea). In addition, serum calcium was measured in all subjects who were taking hydrochlorothiazide (HCTZ:84 participants) at 4 to 6 weeks following study initiation and again at 12 weeks. An additional subset of randomly selected control participants (44 participants), who were not taking HCTZ, also underwent calcium assays at 3 months. Serum total calcium was analyzed using standard auto analyzer methodology. Any participant with serum calcium $>10.5 \mathrm{mg} / \mathrm{dL}$ at the first calcium measurement was immediately discontinued from the study and the primary care physician was notified. If participants had elevated calcium at month 3 (end of supplementation period), they remained in the study. Electronic pill-dispenser systems and pill counts were used to track compliance.

\section{Plasma vitamin D and PTH levels}

Blood samples collected at baseline and 3 months were separated and plasma was stored in liquid nitrogen in the Dana-Farber Cancer Institute Clinical Research Laboratory. In this ancillary analysis, PTH was measured in 254 participants because of lack of stored blood samples for the others. Although the lower number reduces our power and statistical precision, the unavailability of sample is unlikely to cause a bias. All plasma samples were sent as a single batch to the laboratory of Dr. Bruce Hollis 


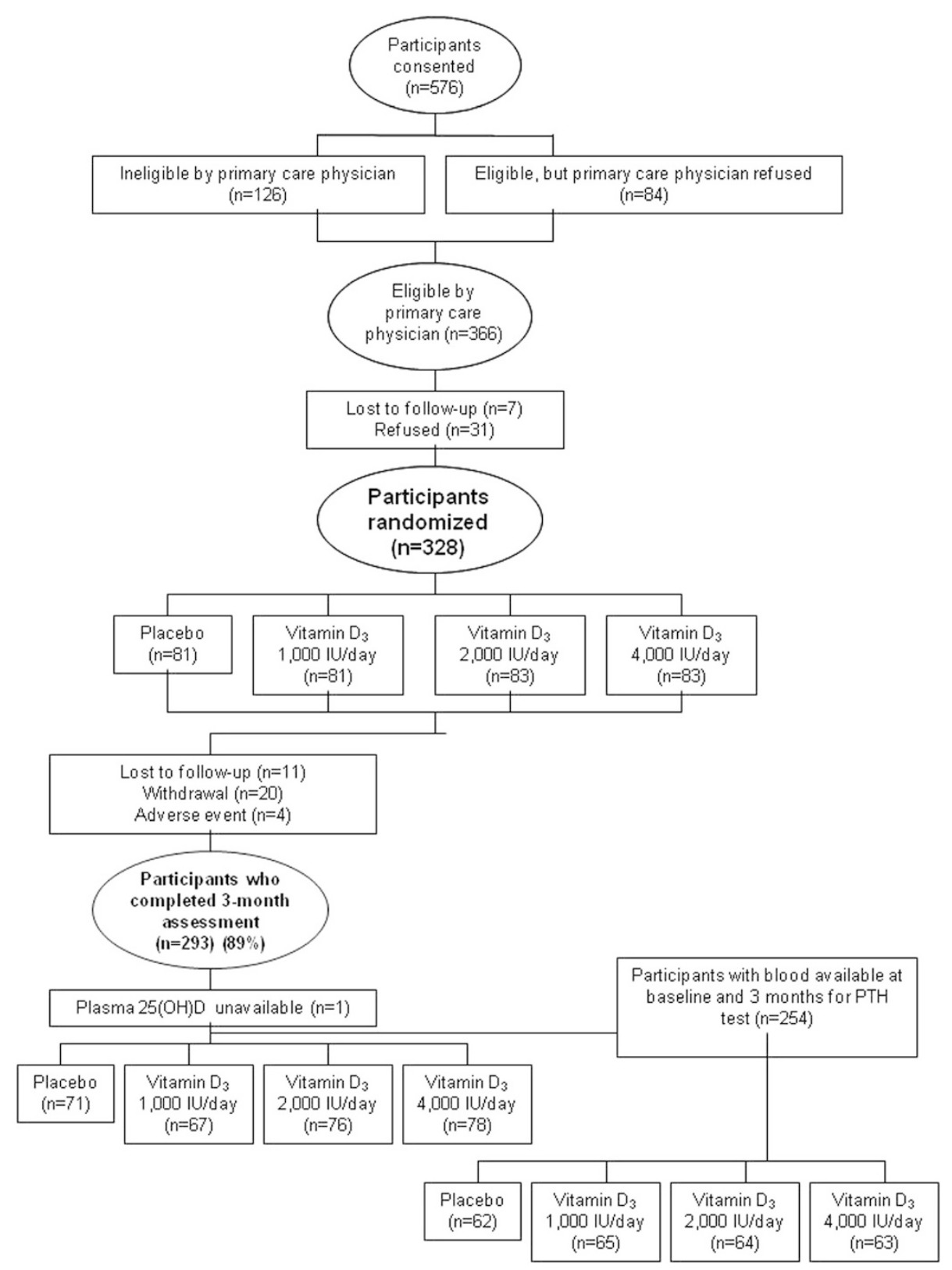

Fig. 1 Consolidated standards of reporting trials diagram

(Medical University of South Carolina, Charleston, SC), where $25(\mathrm{OH}) \mathrm{D}$ concentrations were measured using the Diasorin (DiaSorin, Inc.) radioimmunoassay [24]. The mean coefficient of variation of $25(\mathrm{OH}) \mathrm{D}$ measurements was $9 \%$. Samples for PTH assay were sent as a single batch to Heartland Assays (Ames, Iowa) and measured using the FDA approved DiaSorin intact PTH immunoradiometric assay (IRMA). The intra- and inter-assay CVs for this assay are $2.7 \%$ and $4.3 \%$ respectively. For Heartland Assays, the normal range of PTH is $13-54 \mathrm{pg} / \mathrm{mL}$. For all assays, masked quality control samples were interspersed among the cases and all laboratory personnel were blinded. Of note, the normal range of PTH reported in laboratory manuals is $10-65 \mathrm{pg} / \mathrm{mL}[25,26]$.

\section{Statistical analysis}

This trial has a statistical power of $80 \%$ to detect differences in plasma $25(\mathrm{OH}) \mathrm{D}$ level of $5.3 \mathrm{ng} / \mathrm{mL}$ between treatment groups. All statistical analyses were performed using SAS version 9.2 (SAS Institute, Cary, NC with an intention-to-treat approach. Baseline characteristics of the study population were compared between supplementation arms using Chi-Square test for categorical variables and the Kruskal-Wallis test for continuous 
variables. For our primary analysis, we used linear regression with the dose of vitamin D3 (per 1000 IU/day) as the independent variable and the 3-month change in $\mathrm{PTH}$ as the dependent variable.

We performed a number of a priori secondary analyses. We used linear regression to evaluate the change in PTH according to the change in plasma $25(\mathrm{OH}) \mathrm{D}$ levels. Second, we compared the mean change in PTH between placebo and all three vitamin $\mathrm{D}$ treatment groups combined. Third, we assessed the interaction effect of HCTZ use on the response of PTH to vitamin D supplementation. Fourth, we stratified participants based on baseline $25(\mathrm{OH}) \mathrm{D}(<20 \mathrm{ng} / \mathrm{ml}, \geq 20 \mathrm{ng} / \mathrm{ml})$ and compared PTH change(month 3-month 0), PTH at baseline, and PTH at 3 months. Finally, to assess whether the effect of supplementation with vitamin D on the primary endpoint, 3 month change in PTH, varied according to baseline $25(\mathrm{OH}) \mathrm{D}$, we tested for interaction between treatment group and baseline $25(\mathrm{OH}) \mathrm{D}$ levels.

\section{Results}

Baseline characteristics among the 328 eligible participants are shown in Table 1. The overall median age was 51 years with a median BMI of $31 \mathrm{~kg} / \mathrm{m}^{2}$. The only significant difference in baseline characteristics according to treatment assignment was that slightly more participants in the placebo and $1000 \mathrm{IU} /$ day arms had a past history of cancer than those assigned to 2000 or 4000 IU/day. The compliance with study medication (measured by electronic pill dispenser system and pill counts) in the entire cohort was $96.6 \%$ and did not differ significantly between arms. The 3-month follow-up plasma measurements were completed in 293 of the 328 participants $(89 \%)$. Of the $134 / 328(41 \%)$ of participants

Table 1 Subject characteristics by supplementation $\operatorname{arm}^{\mathrm{a}, \mathrm{b}, \mathrm{g}}$

\begin{tabular}{|c|c|c|c|c|c|}
\hline \multirow[t]{3}{*}{ Characteristic } & \multicolumn{4}{|c|}{ Vitamin D3 Dose Assignment (IU) } & \multirow{3}{*}{ Overall } \\
\hline & PLACEBO & 1,000 & 2,000 & 4,000 & \\
\hline & $(n=81)$ & $(n=81)$ & $(n=83)$ & $(n=83)$ & \\
\hline Age $(y)$ & $50.7(44.1-58.0)^{b}$ & $51.1(43.4-60.1)$ & $50.3(43.5-58.3)$ & $51.3(44.1-59.7)$ & $51.0(43.6-59.4)$ \\
\hline \multicolumn{6}{|l|}{ Sex, No. (\%) } \\
\hline Male & $27(33.3)$ & $22(27.2)$ & $28(33.7)$ & $29(34.9)$ & $106(32.3)$ \\
\hline Female & $54(66.7)$ & $59(72.8)$ & $55(66.3)$ & $54(65.1)$ & $222(67.7)$ \\
\hline BMI $\left(\mathrm{kg} / \mathrm{m}^{2}\right)$ & $31.2(26.5-35.9)$ & $30.5(27.0-37.5)$ & $31.9(26.2-36.9)$ & $31.4(27.4-35.7)$ & $31.2(26.8-36.3)$ \\
\hline \multicolumn{6}{|l|}{ Biomarkers } \\
\hline PTH (pg/mL) & $36.75(30.40-47.20)$ & $35.40(28.90-47.25)$ & $36.40(28.95-47.25)$ & $37.40(29.40-56.40)$ & $36.9(29.4-49.0)$ \\
\hline $25(\mathrm{OHD})(\mathrm{ng} / \mathrm{mL})$ & $15.1(10.4-23.6)$ & $16.2(11.0-22.7)$ & $13.9(9.5-22.3)$ & $15.7(11.0-23.3)$ & $15.3(10.4-22.8)$ \\
\hline \multicolumn{6}{|l|}{ Smoking status, No. (\%) } \\
\hline Never & $33(40.7)$ & $36(44.4)$ & $33(39.8)$ & $44(53.0)$ & $146(44.5)$ \\
\hline Past & $20(24.7)$ & $16(19.8)$ & $27(32.5)$ & $20(24.1)$ & $83(25.3)$ \\
\hline Current & $28(34.6)$ & $29(35.8)$ & $23(27.7)$ & $19(22.9)$ & $99(30.2)$ \\
\hline Frequency of exercise, (day/week) & $3.0(0.5-5.0)$ & $3.0(1.0-5.0)$ & $3.0(0-5.0)$ & $3.0(0-5.0)$ & $3.0(0-5.0)$ \\
\hline Dietary vitamin D intake $(I U)^{c}$ & $147.3(71.4-262.8)$ & $162.5(92.6-295.5)$ & $144.0(58.0-265.1)$ & $198.1(83.2-306.4)$ & $167.5(72.3-291.8)$ \\
\hline Dietary calcium intake $(\mathrm{mg})^{c}$ & $277.0(171.7-632.3)$ & $422.9(226.1-795.9)$ & $318.8(172.7-637.4)$ & $445.9(198.6-780.4)$ & $356.6(188.6-693.8)$ \\
\hline Regular multivitamin use, ${ }^{\mathrm{d}}$ No. (\%) & $10(12)$ & $18(22)$ & $15(18)$ & $22(27)$ & $65(19.8)$ \\
\hline Regular vitamin D supplement use, ${ }^{\mathrm{d}}$ No. (\%) & $8(10)$ & $6(8)$ & $2(2)$ & $8(10)$ & $24(7.3)$ \\
\hline HCTZ use, No. (\%) & 19 & 18 & 12 & 17 & $66(20.1)$ \\
\hline Post-menopausal hormone use, ${ }^{e}$ No. (\%) & 0 & 0 & 0 & $1(0.5)$ & $1(0.5)$ \\
\hline Regular calcium supplement use, ${ }^{d}$ No. (\%) & $7(8.7)$ & $9(11.1)$ & $7(8.4)$ & $9(10.8)$ & $32(9.8)$ \\
\hline History of cancer, ${ }^{f}$ No. (\%) & $6(7.4)$ & $6(7.4)$ & 0 & $3(3.6)$ & $15(4.6)$ \\
\hline History of hypertension, No. (\%) & $35(43.2)$ & $35(43.2)$ & $36(43.3)$ & $35(42.1)$ & $141(43.0)$ \\
\hline
\end{tabular}

${ }^{a}$ There were no significant differences in subject characteristics across supplementation arms except where indicated

${ }^{\mathrm{b}}$ Median; $25^{\text {th }}, 75^{\text {th }}$ percentiles in parentheses (all such values) except otherwise stated

${ }^{\mathrm{c}}$ Refers to the intake during the preceding month of selected calcium-rich foods

${ }^{\mathrm{d}}$ Defined as supplement use for 7 days/week during the preceding month

ePercentages were calculated from a total of 222 females

f Reported cancers include breast cancer, cervical cancer, uterine cancer, lung cancer, prostate cancer, and sarcoma

${ }^{9}$ PTH was measured in 254 individuals

Abbreviations: BMI body mass index, PTH parathyroid hormone, 25(OH)D-25 hydroxyvitamin $\mathrm{D}, H C T Z$ hydrochlorothiazide) 
using anti-hypertensives, 84/134(63\%) participants were on a diuretic, HCTZ.

\section{Effect of vitamin D3 supplementation on plasma 25(OH) D}

Among 328 participants, the median 25(OH)D level at baseline was $15.3 \mathrm{ng} / \mathrm{mL}$. As previously published, baseline plasma $25(\mathrm{OH}) \mathrm{D}$ did not differ significantly between treatment arms $(P=0.63$; Table 2) [27]. Circulating $25(\mathrm{OH}) \mathrm{D}$ levels at 3 months differed significantly by the vitamin D3 supplementation arm, with a median of $14.2,28.1,35.5$, and $47.3 \mathrm{ng} / \mathrm{mL}$ for the placebo, $1000 \mathrm{IU} /$ day, $2000 \mathrm{IU} /$ day, and $4000 \mathrm{IU} /$ day arms, respectively $\quad(P<0.001)$. [Effect estimate \pm SE: $7.7 \pm$ $0.45 \mathrm{ng} / \mathrm{mL}$ for each $1000 \mathrm{IU}$ vitamin D3; P-trend, $0.001]$. Notably, plasma $25(\mathrm{OH}) \mathrm{D}$ decreased at 3 months among participants treated with placebo (Table 2).

\section{Effect of vitamin D on PTH supplementation}

The median [IQR] PTH level at baseline was $36.9 \mathrm{pg} / \mathrm{mL}$ [29.4, 49.0]. At baseline, secondary hyperparathyroidism (defined as PTH $>60 \mathrm{pg} / \mathrm{mL}$ ) was present in 40 participants. Of participants with $25(\mathrm{OH}) \mathrm{D}<20 \mathrm{ng} / \mathrm{mL}, 21.8 \%$ had $\mathrm{PTH} \geq 60 \mathrm{pg} / \mathrm{mL}$ compared to $6.8 \%$ of participants with $25(\mathrm{OH}) \mathrm{D} \geq 20 \mathrm{ng} / \mathrm{mL}$. Plasma PTH did not differ significantly between treatment arms $(P>0.05$; Table 1$)$. Plasma PTH declined with vitamin D supplementation. After 3 months of vitamin D supplementation, participants with $\mathrm{PTH} \geq 60 \mathrm{pg} / \mathrm{mL}$ were $4.6 \%$ for $1000 \mathrm{IU} / \mathrm{d}$, $4.7 \%$ for $2000 \mathrm{IU} / \mathrm{d}$, and $3.2 \%$ for $4000 \mathrm{IU} / \mathrm{d}$ compared to $14.5 \%$ for placebo; $\mathrm{p}$ for trend $=0.03$.
We examined changes in serum PTH according to vitamin D supplementation in several ways. We determined the mean PTH for each arm and calculated the difference between baseline and 3 months follow up. Serum PTH levels at 3 months differed significantly by the vitamin D3 supplementation arm, with a mean of $3.9 \mathrm{pg} / \mathrm{mL},-3.4 \mathrm{pg} / \mathrm{mL},-6.8 \mathrm{pg} / \mathrm{mL}$ and $-9.0 \mathrm{pg} / \mathrm{mL}$ for the placebo, $1000 \mathrm{IU} /$ day, $2000 \mathrm{IU} /$ day, and $4000 \mathrm{IU} /$ day arms, respectively $(-2.98 \mathrm{pg} / \mathrm{mL}$ for each additional $1000 \mathrm{IU} / \mathrm{d}$ of vitamin D3 $p<0.001)$. Using linear regression with the dose of vitamin D3 (per $1000 \mathrm{IU} /$ day) as the independent variable and the $\log _{10} 3$-month change in PTH as the dependent variable, we found a decrease of $-0.07(0.02)$ for each additional $1000 \mathrm{IU} / \mathrm{d}$ of vitamin D3 $(P<0.001)$. (See Additional file 1: Figures S1 and S2) Comparing all three doses $(1000,2000,4000 \mathrm{IU} / \mathrm{d})$ versus placebo, PTH decreased by $-10.30 \mathrm{pg} / \mathrm{mL}(p<0.001)$. Excluding the placebo group, a nonsignificant decrease in PTH occurred at 3 months (PTH: $-1.75 \mathrm{pg} / \mathrm{mL} 95 \%$ CI [-3.59-0.08]; $p=0.06$, for each additional $1000 \mathrm{IU} / \mathrm{d}$ of vitamin D3) versus change in PTH at 3 months including the placebo group $(-2.98 \mathrm{pg} / \mathrm{mL} 95 \% \mathrm{CI}$ $[-4.41,-1.54] ; p<0.001)$.

\section{Relationship between PTH and 25(OH)D}

The relationship between PTH and circulating 25(OH)D was evaluated at baseline and at 3 months. Using a linear regression at baseline, a $1 \mathrm{ng} / \mathrm{mL}$ higher $25(\mathrm{OH}) \mathrm{D}$ was associated with a significant $-0.30 \mathrm{pg} / \mathrm{mL}$ lower PTH $(p=0.01)$. At 3 months, a $1 \mathrm{ng} / \mathrm{mL}$ increase in $25(\mathrm{OH}) \mathrm{D}$ resulted in a significant $-0.23 \mathrm{pg} / \mathrm{mL}$ decrease in PTH

Table 2 Effect of Vitamin D3 Supplementation on PTH (pg/mL) During the Treatment (Baseline to 3 months) ${ }^{\text {a }}$

\begin{tabular}{|c|c|c|c|c|c|c|}
\hline \multirow[b]{2}{*}{ Parameter, mean (SE) } & \multicolumn{4}{|c|}{ Vitamin D Dose, IU/d } & \multirow[b]{2}{*}{3 months Change ${ }^{b}$} & \multirow[b]{2}{*}{ P-Value } \\
\hline & Placebo & 1000 & 2000 & 4000 & & \\
\hline n (at baseline) & 62 & 65 & 64 & 63 & & \\
\hline Total PTH, pg/mL & & & & & $-2.98[-4.41,-1.53]$ & $<0.0001$ \\
\hline Baseline PTH, mean (SE) & $39.40(14.20)$ & $41.15(18.02)$ & $42.21(20.94)$ & $42.96(16.79)$ & & \\
\hline 3 months PTH, mean (SE) & $43.27(18.21)$ & $39.83(15.56)$ & $36.42(15.69)$ & $34.18(12.75)$ & & \\
\hline Difference PTH ${ }^{c}$ mean (SE) & $3.93(18.93)$ & $-3.37(17.84)$ & $-6.76(14.71)$ & $-8.99(12.36)$ & & \\
\hline \multicolumn{7}{|l|}{ 25(OH)D, ng/mL } \\
\hline Baseline 25(OH)D, mean(SE) & $17.07(1.03)$ & $17.33(1.00)$ & $16.12(0.98)$ & $17.79(0.98)$ & $7.57[6.69,8.46]$ & $<0.0001$ \\
\hline 3 months 25(OH)D, mean (SE) & $14.23(0.96)$ & $28.12(1.11)$ & $35.48(1.21)$ & $47.30(1.22)$ & & \\
\hline Difference $25(\mathrm{OH}) \mathrm{D}^{\mathrm{d}}$, mean (SE) & $-2.58(0.66)$ & $11.01(1.22)$ & $19.21(1.21)$ & $29.79(1.29)$ & & \\
\hline \multicolumn{7}{|l|}{ Calcium, mg/dL } \\
\hline 1 month Calcium, mean (SE) & $9.54(0.08)$ & $9.77(0.13)$ & $9.77(0.13)$ & $9.81(0.12)$ & & \\
\hline 3 months Calcium, mean (SE) & $9.57(0.09)$ & $9.59(0.10)$ & $9.59(0.10)$ & $9.77(0.07)$ & & \\
\hline
\end{tabular}

${ }^{\mathrm{a} P T H}$, Parathyroid hormone; mean (SE), mean(Standard Error); IU, international unit. The numbers do not always sum to group totals due to missing information for some variables

${ }^{\mathrm{b}}$ Month3 - Month0 change in PTH per $1000 \mathrm{IU} / \mathrm{d}$ of vitamin D supplementation, Mean (95\% Confidence Interval). Month3 - Month0 change in 25(OH)D per $1000 \mathrm{IU} / \mathrm{d}$ of vitamin D supplementation, Mean (95\% Confidence Interval)

'Difference PTH, Month 3-Month 0 difference in PTH

dDifference 25(OH)D, Month 3- Month 0 difference in 25(OH)D 
$(p=0.0005)$. These models showed a significant inverse relationship between 25(OH)D and PTH. No interaction between baseline 25(OH)D and vitamin $\mathrm{D}$ dose effect on change in PTH was observed ( $\mathrm{p}$ for interaction $=0.15$ ). When baseline $25(\mathrm{OH}) \mathrm{D}$ was stratified, we observed a significant decrease in PTH at 3 months among those with $25(\mathrm{OH}) \mathrm{D}<20 \mathrm{ng} / \mathrm{mL}(-3.76 \mathrm{pg} / \mathrm{mL} 95 \%$ CI [-5.59,-1.92]; $p<0.0001$; for each additional $1000 \mathrm{IU} / \mathrm{d}$ of vitamin D3) and a non-significant decrease among those with $25(\mathrm{OH}) \mathrm{D} \geq 20 \mathrm{ng} / \mathrm{mL}(-1.56 \mathrm{pg} / \mathrm{mL} ; 95 \% \mathrm{CI}[-3.79,0.66]$; $p=0.16$ for each additional $1000 \mathrm{IU} / \mathrm{d}$ of vitamin D3). Comparing baseline PTH level by $25(\mathrm{OH}) \mathrm{D}$ status (deficient versus nondeficient), $25(\mathrm{OH}) \mathrm{D}<20 \mathrm{ng} / \mathrm{mL}: \mathrm{PTH}$ mean (SD), 42.4 (19.9) $\mathrm{pg} / \mathrm{mL}$ versus $39.7(14.0) \mathrm{pg} / \mathrm{mL}$ for $25(\mathrm{OH}) \mathrm{D} \geq 20 \mathrm{ng} / \mathrm{mL} \quad(p=0.24)$. Comparing 3 -month PTH level by $25(\mathrm{OH}) \mathrm{D}$ status, $25(\mathrm{OH}) \mathrm{D}<20 \mathrm{ng} / \mathrm{mL}$ : PTH mean (SD), 38.1(17.7) pg/mL versus 38.9 (12.0) pg/ $\mathrm{mL}$ for $25(\mathrm{OH}) \mathrm{D} \geq 20 \mathrm{ng} / \mathrm{mL}(p=0.72)$. No significant interaction between HCTZ use and change in PTH with vitamin D supplementation was observed ( $\mathrm{p}$ for interaction $=0.59$ ). Plasma PTH declined in HCTZ and nonHCTZ users (HCTZ:-4.2 pg/mL 95 \% CI [-7.6,-0.85]; $p=$ 0.02 ; for each additional $1000 \mathrm{IU} / \mathrm{d}$ of vitamin D3; nonHCTZ: $-2.51 \mathrm{pg} / \mathrm{mL} 95 \%$ CI [-4.07,-0.96]; $p=0.002$ ).

\section{Adverse effects}

We previously reported the hypercalcemia events [28]. Briefly, after 1 month of the 12-week vitamin D supplementation period, 4 participants taking HCTZ experienced modestly elevated serum calcium levels, ranging from 10.7 to $11.0 \mathrm{mg} / \mathrm{dL}$. At 3-months, only one HCTZ participant had elevated calcium (calcium $=11.2 \mathrm{mg} / \mathrm{dL}$ ). There were no significant differences in calcium concentrations between treatment arms at 1 month $(P=0.14)$ and 3 months $(P=0.52)$.

\section{Discussion}

Black Americans have significantly lower 25(OH)D and higher PTH concentrations than Whites [1,2]. We evaluated the hypothesis that vitamin $\mathrm{D}$ supplementation reduces PTH in Blacks. PTH has been shown to be a sensitive biomarker of vitamin $\mathrm{D}$ activity in vivo [17]. At baseline, we found a significant inverse association between serum 25(OH)D and PTH similar to prior crosssectional studies [2]. Vitamin D supplementation led to an increase in circulating $25(\mathrm{OH}) \mathrm{D}$ in this vitamin $\mathrm{D}$ deficient Black population and a decrease in PTH in a dose-dependent manner confirming the presence of vitamin D deficiency based on PTH criteria. Vitamin D deficiency is defined as $25(\mathrm{OH}) \mathrm{D}$ less than $20 \mathrm{ng} / \mathrm{mL}$ by IOM, and it provides no formal guidelines regarding vitamin D screening [29]. The USPTF gives no recommendation for or against screening and treating asymptomatic individuals for vitamin D deficiency, because the evidence regarding the benefits and harms is insufficient [12].

Vitamin D supplementation had a strong and unequivocal effect in lowering PTH when baseline levels were $<20 \mathrm{ng} / \mathrm{mL}$ but a weaker and non-significant decrease for $25(\mathrm{OH}) \mathrm{D}>20 \mathrm{ng} / \mathrm{mL}$. This finding suggests that a reduction in $\mathrm{PTH}$ is clear when $25(\mathrm{OH}) \mathrm{D}$ greater than or equal to $20 \mathrm{ng} / \mathrm{mL}$ is attained; a more modest lowering effect is possible with 25(OH)D levels higher than $20 \mathrm{ng} / \mathrm{mL}$. A large cross-sectional analysis of 312,962 paired serum PTH and 25-OHD (no information provided about race/ethnicity) similarly found significant continuing declines in serum PTH levels beyond 20 and $30 \mathrm{ng} / \mathrm{ml}$ of $25(\mathrm{OH}) \mathrm{D}$ [30], but a larger study than ours would be required to test this definitively. In terms of vitamin D dose needed to maximally suppress $\mathrm{PTH}$, an effect is clear with supplementation of at least $1000 \mathrm{IU} /$ day (e.g., comparing all three doses $(1000,2000$, $4000 \mathrm{IU} / \mathrm{d})$ versus placebo, PTH decreased by $-10.30 \mathrm{pg} /$ $\mathrm{mL}(p<0.001))$. When excluding the placebo group, and thereby assessing the effect of vitamin $\mathrm{D}$ over a range of 1000 to $4000 \mathrm{IU}$, a nonsignificant decrease in PTH occurred (PTH: -1.75 pg/mL $95 \%$ CI [-3.59-0.08]; $p=0.06$, for each additional $1000 \mathrm{IU} / \mathrm{d}$ of vitamin D3). Thus, our results suggest that intakes higher than $1000 \mathrm{IU} / \mathrm{d}$ may be required to maximally suppress PTH in Blacks. Of note, in this population, we estimated 1640 IU vitamin D3/d was needed to raise the plasma $25(\mathrm{OH}) \mathrm{D}$ concentration to $\geq 20 \mathrm{ng} / \mathrm{mL}$ in $\geq 97.5 \%$ of participants [27].

In agreement with our findings, a systematic review of clinical trials on the response of parathyroid hormone to vitamin D supplementation shows that PTH decreases linearly during vitamin $\mathrm{D}$ supplementation for any given 25(OH)D level [31]. Furthermore, the review suggests that longitudinal vitamin $\mathrm{D}$ supplementation studies on populations with wide range of mobility and age are needed to further elucidate their modifying effects and the inter-individual variation in responses of PTH to vitamin D supplementation [31].

The IOM Report [10,11] and the Endocrine Society Clinical Practice Guideline [32] both agree that providing vitamin $\mathrm{D}$ for any reason other than bone health is not supported by current published literature. The main way in which the two reports differ is on the upper threshold for which vitamin D is safe. For the IOM, the upper threshold is $50 \mathrm{ng} / \mathrm{mL}$ but for the Endocrine Society it is $100 \mathrm{ng} / \mathrm{mL}$ [32]. The basis for their difference is driven by the interpretation of elevated PTH levels. Controversy remains on how these thresholds were selected [33]. Neither report recommends vitamin D supplementation when PTH levels are in the normal range. The IOM Committee concluded that the evidence that vitamin D or calcium reduced risk of nonskeletal chronic disease outcomes is inconsistent, inconclusive, and did 
not meet criteria for establishing cause-and-effect relationship [10, 11]. Furthermore, the Endocrine Society states that there is not sufficient evidence to recommend screening individuals who are not at risk for deficiency to prescribe vitamin $\mathrm{D}$ to attain the noncalcemic benefit for cardiovascular protection [32].

Few studies have examined the relationship between vitamin D supplementation and PTH in Blacks. In a study of 127 postmenopausal Black women randomized to either placebo or $1000 \mathrm{IU}$ of vitamin D supplementation with calcium supplement to bring daily calcium intake to $1000 \mathrm{mg}$, serum 25(OH)D increased by $100 \%$ in supplement users from a baseline of $11.6 \mathrm{ng} / \mathrm{mL}$ and produced a significant decline in PTH at 3 months [34]. In another study of 198 White and African-American women, participants were randomly assigned to placebo or daily vitamin $\mathrm{D}$ supplementation and were given calcium to maintain total calcium intake of $1000-1200 \mathrm{mg} / \mathrm{d}$. At 12 months, the investigators concluded that a vitamin D dose of $400 \mathrm{IU} / \mathrm{d}$ increased serum $25(\mathrm{OH}) \mathrm{D}$ to greater than $20 \mathrm{ng} / \mathrm{mL}$ in $97.5 \%$ of Whites while 800 to $1600 \mathrm{IU} / \mathrm{d}$ was required to reach the same effect in African Americans [35]. They also found that that serum PTH reduced significantly in both races over time but the change was not dose dependent [35].

Reduced bone turnover and reduced risk of osteoporotic fractures in Black women compared to White women $[36,37]$ have resulted in the suggestion of a lower cutpoint for normal serum 25(OH)D in Blacks. In contrast, the Women's Health Initiative (WHI) nested case-control study suggested that $25(\mathrm{OH}) \mathrm{D}$ greater than $20 \mathrm{ng} / \mathrm{mL}$ is associated with increased fractures in Blacks [38], but the cases had about $50 \%$ more treated diabetes than the controls (11\% versus $16 \%$, difference between groups $p=0.05$ ) and diagnosed diabetes is associated with greater risk of fractures in Blacks than Whites [39]. Furthermore, they could not test whether the association between low 25(OH)D levels and fracture was independent of BMD because only three WHI clinics measured BMD [38]. Interestingly, this WHI study found no association between PTH and fracture risk in any ethnic group [38]. Yet, recent studies have implicated low $25(\mathrm{OH}) \mathrm{D}$ in increased all-cause and cause-specific mortality in both Blacks and Whites [40-44].

Furthermore, although Blacks have been shown to be less sensitive to the effects of PTH on bone turnover [45], serum PTH levels have been shown to be an independent risk factor for cardiovascular events, cardiovascular mortality, and all-cause mortality, even in individuals with PTH within the normal or slightly elevated range [7, 46-49]. A community-based prospective study of 958 elderly men found that higher plasma levels of PTH were associated with higher risk for cardiovascular mortality independently of established cardiovascular risk factors and factors associated with mineral homeostasis. The results remained significant in participants with PTH within the normal range. Thus, PTH levels may portray prognostic information even in the absence of primary or secondary hyperparathyroidism [7]. In the health $\mathrm{ABC}$ study, elevated PTH $(\geq 70 \mathrm{pg} / \mathrm{mL})$ was associated with increased all-cause, CVD, and noncancer, non-CVD mortality in Black and White communitydwelling older adults [6].

Strengths of the study include the use of multiple doses of vitamin $\mathrm{D}$ supplementation during winter months and the use of an all Black cohort. Limitations of our study include the use of a population with low calcium intake. Thus, it may not be generalizable to populations with higher calcium intake. In addition, we studied only a short duration of supplementation with 3 doses of vitamin D3 (highest dose 4000 IU/d). Lastly, this study shows that vitamin D supplementation changes vitamin D and PTH levels, but it has no outcome measure as to long term effect on health of changing either vitamin D or PTH levels and this is a major limitation of the study design. However, our previous work showed that vitamin D supplementation in this cohort reduced blood pressure [20] without causing hypercalcemia even in HCTZ users [28].

\section{Conclusions}

This study highlights a dose-dependent decrease in PTH in Blacks with vitamin D supplementation confirming correction of low vitamin $\mathrm{D}$, but whether reduction of PTH should be done or is safe to do is unproven. Identification of optimal levels of plasma 25(OH)D and PTH remain to be established.

\section{Additional file}

Additional file 1: Figure S1. Log Change of PTH (Month 3-Month 0) by
Vitamin D Dose/day. Figure S2. Change in PTH (Month 3- Month 0) by
Vitamin D Dose/day. (PDF $201 \mathrm{~kb}$ )

Abbreviations

PTH: Parathyroid hormone; 25(OH)D: 25-hydroxyvitamin D; IOM: Institute of Medicine; WHI: Women's Health Initiative; CVD: Cardiovascular disease; DM: Diabetes mellitus; USPSTF: U.S. Preventive Services Task Force; RCT: Randomized clinical trial; FFQ: Food frequency questionnaire; IRMA: Immunoradiometric assay; HCTZ: Hydrochlorothiazide; BMI: Body mass index.

\section{Competing interests}

Dr. Hollis has received support from DiaSorin S.p.A for serving as an academic consultant. No other relevant financial disclosures or conflicts of interest were reported by the authors for themselves or their spouses, partners, or children.

\section{Authors' contributions}

PC: Data acquisition, data analysis, draft, review and editing of manuscript PC takes responsibility for the integrity of the data and the accuracy of the data analysis. FA: Draft, review and editing of manuscript. KN: Review and editing of manuscript. JS: Review and editing of manuscript. BD: Study 
design, data acquisition, data analysis, review and editing of manuscript. GB: Study design, review and editing of manuscript. AC: Review and editing of manuscript. BH: Review and editing of manuscript. KE: Study design, review and editing of manuscript. CF: Study design, review and editing of manuscript. EG: Study design, data analysis, review and editing of manuscript. All authors read and approved the final manuscript.

\section{Acknowledgements}

This trial was funded by the National Cancer Institute (U01CA138962 [Dr. Chandler];P50CA127003; K07CA148894 [Dr Ng]; K22CA126992; 5K05CA124415 [Dr Emmons]; K24DK098311 [Dr. Chan]), the Department of Defense Prostate Cancer Research Program (PC081669 [Dr Drake]), the American Society of Clinical Oncology Career Development Award (Dr Ng), the Pure North S'Energy Foundation (Calgary, Alberta, Canada) and Pharmavite LLC (Mission Hill, CA). These funding sources had no role in the conception or conduct of the study, took no part in the data collection or analysis, and had no role in the drafting, review, or approval of the article. Clinical Trials.gov: NCT00585637. This work was conducted with support from Harvard Catalyst | The Harvard Clinical and Translational Science Center (NCRR and NCATS, NIH Award UL1 TR001102) and financial contributions from Harvard University and its affiliated academic healthcare centers.

\section{Author details}

'Division of Preventive Medicine, Brigham and Women's Hospital, Third Floor, 900 Commonwealth Avenue, Boston, MA 02215, USA. ${ }^{2}$ Harvard Medical School, Boston, MA, USA. ${ }^{3}$ Division of Policy Translation and Leadership Development, Harvard School of Public Health, Boston, MA, USA.

${ }^{4}$ Department of Medical Oncology, Dana-Farber Cancer Institute, Boston, MA, USA. ${ }^{5}$ Department of Epidemiology and Biostatistics, College of Human Medicine, Michigan State University, East Lansing, MI, USA. ${ }^{6}$ Department of Surgery, Division of Public Health Sciences, Washington University School of Medicine, St. Louis, MO, USA. ${ }^{7}$ Department of Psychology and Neuroscience, Duke University, Durham, NC, USA. ${ }^{8}$ Division of Gastroenterology, Massachusetts General Hospital, Boston, MA, USA. 'Division of Pediatrics, Medical University of South Carolina, Charleston, SC, USA. ${ }^{10}$ Center for Community-Based Research, Dana-Farber Cancer Institute, Boston, MA, USA. ${ }^{11}$ Channing Division of Network Medicine, Department of Medicine, Brigham and Women's Hospital, Boston, USA. ${ }^{12}$ Departments of Nutrition and Epidemiology, Harvard School of Public Health, Boston, MA, USA.

Received: 27 April 2015 Accepted: 9 October 2015

Published online: 17 December 2015

\section{References}

1. Gutierrez OM, Farwell WR, Kermah D, Taylor EN. Racial differences in the relationship between vitamin $\mathrm{D}$, bone mineral density, and parathyroid hormone in the National Health and Nutrition Examination Survey. Osteoporos Int. 2011;22(6):1745-53.

2. Nesby-O'Dell S, Scanlon KS, Cogswell ME, Gillespie C, Hollis BW, Looker AC, et al. Hypovitaminosis D prevalence and determinants among African American and white women of reproductive age: third National Health and Nutrition Examination Survey, 1988-1994. Am J Clin Nutr. 2002;76(1):187-92.

3. Holick MF. Vitamin D, and bone health. J Nutr. 1996;126(4 Suppl):1159S-64S.

4. Mezquita-Raya P, Munoz-Torres M, Luna JD, Luna V, Lopez-Rodriguez F, Torres-Vela $\mathrm{E}$, et al. Relation between vitamin D insufficiency, bone density, and bone metabolism in healthy postmenopausal women. J Bone Miner Res. 2001;16(8):1408-15.

5. Cosman F, Morgan DC, Nieves JW, Shen V, Luckey MM, Dempster DW, et al. Resistance to bone resorbing effects of PTH in black women. J Bone Miner Res. 1997;12(6):958-66.

6. Kritchevsky SB, Tooze JA, Neiberg RH, Schwartz GG, Hausman DB, Johnson MA, et al. 25-Hydroxyvitamin D, parathyroid hormone, and mortality in black and white older adults: the health ABC study. J Clin Endocrinol Metab. 2012;97(11):4156-65.

7. Hagstrom E, Hellman P, Larsson TE, Ingelsson E, Berglund L, Sundstrom J, et al. Plasma parathyroid hormone and the risk of cardiovascular mortality in the community. Circulation. 2009;119(21):2765-71.

8. Eastell R, Arnold A, Brandi ML, Brown EM, D'Amour P, Hanley DA, et al. Diagnosis of asymptomatic primary hyperparathyroidism: proceedings of the third international workshop. J Clin Endocrinol Metab. 2009;94(2):340-50.
9. Rosen CJ. Clinical practice. Vitamin D insufficiency. N Engl J Med. 2011;364(3):248-54.

10. Ross AC, Manson JE, Abrams SA, Aloia JF, Brannon PM, Clinton SK, et al. The 2011 report on dietary reference intakes for calcium and vitamin D from the Institute of Medicine: what clinicians need to know. J Clin Endocrinol Metab. 2011;96(1):53-8.

11. Institute of Medicine. Dietary reference intakes for calcium and vitamin D. Washington, D.C.: National Academies Press; 2011.

12. Moyer VA, Force* USPST. Vitamin D and calcium supplementation to prevent fractures in adults: U.S. Preventive Services Task Force recommendation statement. Ann Intern Med. 2013;158(9):691-6.

13. Chen $G$, Xue $Y$, Zhang Q, Xue T, Yao J, Huang $H$, et al. Is normocalcemic primary hyperparathyroidism harmful or harmless? J Clin Endocrinol Metab. 2015;100(6):2420-4.

14. Kang MG, Won EJ, Choi HW, Kim HR, Choi HJ, Park HR, et al. Serum parathyroid hormone is a new potential risk factor in multiple myeloma. Biomed Res Int. 2014;2014:804182.

15. Huang C, Shapses SA, Wang X. Association of plasma parathyroid hormone with metabolic syndrome and risk for cardiovascular disease. Endocr Pract. 2013;19(4):712-7.

16. Yan H, Sharma J, Weber CJ, Guyton RA, Perez S, Thourani VH. Elevated parathyroid hormone predicts mortality in dialysis patients undergoing valve surgery. Surgery. 2011;150(6):1095-101.

17. Saliba W, Barnett O, Rennert HS, Lavi I, Rennert G. The relationship between serum 25(OH)D and parathyroid hormone levels. Am J Med. 2011;124(12):1165-70.

18. Kucharska-Newton AM, Rosamond WD, Schroeder JC, McNeill AM, Coresh J, Folsom AR, et al. HDL-cholesterol and the incidence of lung cancer in the Atherosclerosis Risk in Communities (ARIC) study. Lung Cancer. 2008;61(3):292-300.

19. Gaffney-Stomberg E, Lutz LJ, Rood JC, Cable SJ, Pasiakos SM, Young AJ, et al. Calcium and vitamin D supplementation maintains parathyroid hormone and improves bone density during initial military training: a randomized, double-blind, placebo controlled trial. Bone. 2014;68:46-56.

20. Forman JP, Scott JB, Ng K, Drake BF, Suarez EG, Hayden DL, et al. Effect of vitamin D supplementation on blood pressure in blacks. Hypertension. 2013;61(4):779-85.

21. U.S. Census Bureau. Overview of race and Hispanic origin. Census 2000 Brief, 2001 (March 2001). Available online: https://www.census.gov/prod/ 2001pubs/c2kbr01-1.pdf(accessed on 28 September, 2015).

22. McKenney NR, Bennett CE. Issues regarding data on race and ethnicity: the Census Bureau experience. Public Health Rep. 1994;109(1):16-25.

23. Williams DR. Race/ethnicity and socioeconomic status: measurement and methodological issues. Int J Health Serv. 1996;26(3):483-505.

24. Hollis BW. Quantitation of 25-hydroxyvitamin D and 1,25-dihydroxyvitamin $D$ by radioimmunoassay using radioiodinated tracers. Methods Enzymol. 1997:282:174-86.

25. Fischbach FT, Dunning MB. A manual of laboratory and diagnostic tests. Philadelphia: Wolters Kluwer Health/Lippincott Williams \& Wilkins; 2009.

26. Martin LJ, Melnichouk O, Huszti E, Connelly PW, Greenberg CV, Minkin S, et al. Serum lipids, lipoproteins, and risk of breast cancer: a nested case-control study using multiple time points. J Natl Cancer Inst. 2015;107(5)djv032.

27. Ng K, Scott JB, Drake BF, Chan AT, Hollis BW, Chandler PD, et al. Dose response to vitamin $D$ supplementation in African Americans: results of a 4-arm, randomized, placebo-controlled trial. Am J Clin Nutr. 2014:99(3):587-98.

28. Chandler PD, Scott JB, Drake BF, Ng K, Forman JP, Chan AT, et al. Risk of hypercalcemia in blacks taking hydrochlorothiazide and vitamin D. Am J Med. 2014;127(8):772-8.

29. Rosen CJ, Abrams SA, Aloia JF, Brannon PM, Clinton SK, Durazo-Arvizu RA, et al. IOM committee members respond to Endocrine Society vitamin D guideline. J Clin Endocrinol Metab. 2012;97(4):1146-52.

30. Valcour A, Blocki F, Hawkins DM, Rao SD. Effects of age and serum 25-OH-vitamin D on serum parathyroid hormone levels. J Clin Endocrinol Metab. 2012;97(11):3989-95.

31. Bjorkman M, Sorva A, Tilvis R. Responses of parathyroid hormone to vitamin D supplementation: a systematic review of clinical trials. Arch Gerontol Geriatr. 2009;48(2):160-6.

32. Holick MF, Binkley NC, Bischoff-Ferrari HA, Gordon CM, Hanley DA, Heaney $\mathrm{RP}$, et al. Evaluation, treatment, and prevention of vitamin D deficiency: an 
Endocrine Society clinical practice guideline. J Clin Endocrinol Metab. 2011;96(7):1911-30.

33. Heaney RP, Holick MF. Why the IOM recommendations for vitamin D are deficient. J Bone Miner Res. 2011;26(3):455-7.

34. Meyer HE, Smedshaug GB, Kvaavik E, Falch JA, Tverdal A, Pedersen JI. Can vitamin $\mathrm{D}$ supplementation reduce the risk of fracture in the elderly? A randomized controlled trial. J Bone Miner Res. 2002;17(4):709-15.

35. Arulselvan P, Wen CC, Lan CW, Chen YH, Wei WC, Yang NS. Dietary administration of scallion extract effectively inhibits colorectal tumor growth: cellular and molecular mechanisms in mice. PLoS One. 2012;7(9):e44658.

36. Aloia JF, Mikhail M, Pagan CD, Arunachalam A, Yeh JK, Flaster E. Biochemical and hormonal variables in black and white women matched for age and weight. J Lab Clin Med. 1998;132(5):383-9.

37. Cosman F, Nieves J, Dempster D, Lindsay R. Vitamin D economy in blacks. J Bone Miner Res. 2007;22 Suppl 2:V34-8.

38. Cauley JA, Danielson ME, Boudreau R, Barbour KE, Horwitz MJ, Bauer DC, et al. Serum 25-hydroxyvitamin D and clinical fracture risk in a multiethnic cohort of women: the Women's Health Initiative (WHI). J Bone Miner Res. 2011;26(10):2378-88.

39. Looker AC, Eberhardt MS, Saydah SH. Diabetes and fracture risk in older U.S. adults. Bone. 2015:58756-3282(14)00460-8.

40. Fiscella K, Franks P. Vitamin D, race, and cardiovascular mortality: findings from a national US sample. Ann Fam Med. 2010;8(1):11-8.

41. Fiscella K, Winters P, Tancredi D, Hendren S, Franks P. Racial disparity in death from colorectal cancer: does vitamin D deficiency contribute? Cancer. 2011;117(5):1061-9.

42. Giovannucci E, Liu Y, Willett WC. Cancer incidence and mortality and vitamin D in black and white male health professionals. Cancer Epidemiol Biomarkers Prev. 2006;15(12):2467-72.

43. Harris SS. Vitamin D, and African Americans. J Nutr. 2006;136(4):1126-9.

44. Lappe JM, Travers-Gustafson D, Davies KM, Recker RR, Heaney RP. Vitamin D and calcium supplementation reduces cancer risk: results of a randomized trial. Am J Clin Nutr. 2007;85(6):1586-91.

45. Nieves JW, Cosman F, Grubert E, Ambrose B, Ralston SH, Lindsay R. Skeletal effects of vitamin D supplementation in postmenopausal black women. Calcif Tissue Int. 2012;91(5):316-24.

46. Kovesdy CP, Ahmadzadeh S, Anderson JE, Kalantar-Zadeh K. Secondary hyperparathyroidism is associated with higher mortality in men with moderate to severe chronic kidney disease. Kidney Int. 2008;73(11):1296-302.

47. Sambrook PN, Chen JS, March LM, Cameron ID, Cumming RG, Lord SR, et al. Serum parathyroid hormone is associated with increased mortality independent of 25-hydroxy vitamin d status, bone mass, and renal function in the frail and very old: a cohort study. J Clin Endocrinol Metab. 2004;89(11):5477-81.

48. Sambrook PN, Chen JS, March LM, Cameron ID, Cumming RG, Lord SR, et al. Serum parathyroid hormone predicts time to fall independent of vitamin D status in a frail elderly population. J Clin Endocrinol Metab. 2004;89(4):1572-6.

49. Tentori F, Blayney MJ, Albert JM, Gillespie BW, Kerr PG, Bommer J, et al. Mortality risk for dialysis patients with different levels of serum calcium, phosphorus, and PTH: the Dialysis Outcomes and Practice Patterns Study (DOPPS). Am J Kidney Dis. 2008;52(3):519-30

\section{Submit your next manuscript to BioMed Central and take full advantage of:}

- Convenient online submission

- Thorough peer review

- No space constraints or color figure charges

- Immediate publication on acceptance

- Inclusion in PubMed, CAS, Scopus and Google Scholar

- Research which is freely available for redistribution 